\title{
A Literature Review on the Culture of Cheating in Undergraduate Engineering Programs
}

\author{
David M. Smith, Susan Bens, Douglas Wagner, and Sean Maw \\ University of Saskatchewan \\ sean.maw@usask.ca
}

\begin{abstract}
Anecdotally, cheating is perceived to happen in all Canadian engineering programs in varying degrees. The authors of this study want to understand the cultures of cheating in the Engineering Colleges at the Universities of Saskatchewan and Regina, to inform efforts to reduce the prevalence of cheating. The first step that has been undertaken in this process is a literature review of previous studies on the general topic of cheating in undergraduate engineering programs.

As it happens, virtually all of these studies have taken place in the United States, further motivating parallel work here in Canada. Surveys have recently been distributed to students and faculty at the Universities of Saskatchewan and Regina, where the content of those surveys has been strongly influenced by high-quality work carried out by American researchers of this topic.

In this paper, we will describe the research work that has been performed previously, and the survey and measurement tools that have been utilized in past studies e.g. PACES-1, PACES-2 and SEED. The general and specific methods that have been employed will be described, and the results will be summarized. For example, it is known that faculty and students often have very different definitions of, and beliefs around, cheating. In practical terms, this manifests itself in the differing attributions of responsibility for cheating.

We conclude our paper by constructing a concise framework that summarizes the current understandings of how cheating is defined in an academic context for engineering, the most common ethical footings that underlie those definitions, and the conditional behaviours that result from them. Finally, we speculate on the potential differences that may arise in a Canadian context, and we describe the approach that we have taken to studying cheating at our own institutions using surveys and other evaluative processes.
\end{abstract}

Keywords: cheating, academic integrity, engineering, education

\section{INTRODUCTION}

Cheating damages engineering schools in three fundamental ways. It short-circuits the achievement of learning objectives, it erodes the integrity of the evaluation system that is the basis for professional accreditation, and it demoralizes those community members who do not cheat. As such, cheating (or academic dishonesty) is a serious issue. However, it has also been persistent in its presence over the years to the point where it is often grudgingly accepted as being part of the system, much like doping is in sports.

Academic dishonesty has been studied quite extensively in American engineering schools [2] [5] [9] [12] [22]. It has not, however, been studied to the same extent in Canada. We recognize that cheating is present here and that there may be differences in how cheating manifests itself in Canadian engineering schools. For this reason, the engineering schools at the Universities of Saskatchewan and Regina have undertaken a program to study academic dishonesty in Canada. The first survey instrument that has been used is very similar to those initially employed in American schools. Having completed a successful data collection recently, the authors look forward to sharing these results soon.

For now, this paper presents the precursor work to our initial survey by summarizing and interpreting the literature on cheating in undergraduate engineering programs, predominantly in an American context. For comparison, some data is included from other academic disciplines, but the main focus will be engineering. We will first review the prevalence of academic dishonesty in engineering programs. We will then review demographic issues in cheating, as well as the situational and contextual factors influencing student academic dishonesty. We will finish by reviewing ways in which cheating can be inhibited, and by describing our initial survey, the results of which should be available by September 2016.

There are three main survey tools that have been used in American studies to analyze academic dishonesty in engineering. These three surveys were developed by Dr. Trevor Harding and his colleagues in the Exploring Ethical decision-making in Engineering (or $\mathrm{E}^{3}$ ) research group. 
The first was the Perceptions and Attitudes toward Cheating among Engineering Students (PACES-1) survey. PACES-1 was used in a survey of 643 undergraduate engineering students at 11 institutions in the US and abroad [5]. It was a general investigation into undergraduate cheating and what students and faculty consider to be academic dishonesty. The second survey tool, PACES-2, was completed by 388 engineering undergraduates at three institutions in the Midwestern US [12]. PACES-2 was an exploration of the variables that predict test cheating among engineering undergraduate students. The final survey tool we reviewed was the Student Engineering Ethical Development (SEED) survey which had 3914 respondents at 18 US institutions [9]. The goal of SEED was to develop a conceptual framework of the ethical development of engineering undergraduates.

Before beginning a discussion of the prevalence of academic dishonesty, a couple of key points should be noted. Cheating is a very relative and nuanced concept. Ask any set of students, or faculty, and you will get a variety of opinions as to what precisely constitutes cheating. Some of those responses will also change with circumstance. For many, it is a matter of degree. We may each be quite firm in our convictions regarding what constitutes cheating but the fact remains, the variety of opinions on the matter is quite extensive. Since one's definition of "academic dishonesty" can be the basis for ethical decisions regarding this type of behaviour, it is often only possible to reach consensus in the most extreme of cases. Keep these ideas in mind as we plumb the depths of the culture of cheating in undergraduate engineering programs, predominantly in an American context.

\section{THE PREVELANCE OF ACADEMIC DISHONESTY IN ENGINEERING}

Cheating is not a new problem, and it can take many forms. Large-scale studies of self-reported rates of academic dishonesty have been conducted in the US and elsewhere. In the Canadian context, a survey of students at 11 postsecondary institutions found the most common cheating behaviours among undergraduate students to include: working with others when asked for individual work (45\%), getting questions and answers from someone who has already taken a test (38\%), copying a few sentences of material from a written source without footnoting (37\%), copying a few sentences from the internet without footnoting $(35 \%)$, and fabricating or falsifying lab data $(25 \%)$ [7].

Findings of studies focused on engineering students are fewer in number, but also raise concern. Research has found engineering students self-report engaging in more acts of academic dishonesty and at higher rates than students in other programs, placing engineering students second only to business students in this regard [19] [22].
The $\mathrm{E}^{3}$ team of researchers used PACES-1 to study selfreported incidence and perceptions among engineering students and the team has published in a number of engineering education and higher education conference proceedings and journals [5] [22]. In 2006, the $\mathrm{E}^{3}$ team reported that $96 \%$ of surveyed students admitted to knowingly engaging in behaviour widely regarded as cheating. Furthermore, they found that despite almost all students recognizing that copying another's homework is cheating, 32\% admitted to doing it at least once in a one term period [5]. A relatively small number of other researchers have used this same survey instrument, and found similar results with only minor variations [3] [18].

Expanding the reach to almost 4,000 US-based engineering students with the SEED survey, Finelli et al. [9] found that $79 \%$ of the students reported engaging in at least one of the following behaviours: test-cheating (24\%), cheating on problem sets $(45 \%)$, cheating on lab reports (20\%), cheating on written assignments (7\%), taking advantage of group members $(21 \%)$, and lying to a professor about academic work $(14 \%)$. With respect to perceptions of peer behaviour, $64 \%$ of engineering student respondents said they knew about cheating by another student and did not report it [9].

\section{DEMOGRAPHIC FACTORS THAT INFLUENCE ACADEMIC DISHONESTY}

The results of the PACES-1 and PACES-2 surveys have pointed to several demographic factors that are possible indicators of academic dishonesty. These include gender, year of study, extracurricular involvement, academic average, and international status.

In Canada, the majority of engineering students in most programs are male. Statistics Canada reported in 2011 that only $23 \%$ of graduates aged 25 to 34 in Canada were female [11]. Since male students typically self-report cheating more often than female students [4] [17] [20], perhaps the higher proportion of males explains findings of greater incidence of academic dishonesty in engineering programs. Results of the PACES-1 survey found a small gender influence on engineering students' inclination to engage in academic dishonesty with male students selfreporting cheating more often than females [22]. However, some recent research with students in other programs has found no difference between male and female academic dishonesty and explain this by observing convergence of academic behaviour of men and women [16]. As the trends in engineering demographics change, so may the rates of academic dishonesty.

The research on engineering students has been mixed regarding the differences between upper-years and firstyears. The results from PACES-2 found that freshman (first-year) engineering students cheated more than senior students [12]. However, this is counter to results from PACES-1 where first-year students reported cheating on 
exams less than upper-year students [22]. Research on other majors has generally pointed to first-year students being academically dishonest more often than upper-years [10] [20]. Additional research on the year of study in which students are more likely to engage in academic dishonesty could help direct the timing of ethics education in engineering schools.

Higher amounts of extracurricular involvement are another factor that may predict a higher predisposition towards academic dishonesty [4] [10] [20]. The reason often given is that as students spend more time in these activities, they have less time for their studies, leading them to cheat as a time-saving strategy [20]. This is of special interest to engineering as the average workload of students is generally quite high. Engineering students often point to their intense workloads and associated stresses as a reason for cheating [19]. Results from the PACES-1 survey reported that students highly involved in extracurricular activities demonstrated greater levels of examination cheating [22]. The research thus far has shown that high levels of extracurricular involvement correlate with an increased likelihood that an engineering student will exhibit dishonest academic behaviour.

The PACES-1 survey found that engineering students with higher academic averages self-reported less cheating compared to those with lower averages [22]. This matches research conducted with students in other programs [4] [10] [14] [20]. An explanation for this trend is that struggling students will rely more on academic dishonesty as they have less to lose by cheating and are more likely to take the risk of getting caught [17]. As mentioned earlier, engineering students often cite heavy workloads as an excuse for cheating. Engineering students with lower averages who are struggling with their workloads could be at higher risk for academic dishonesty on exams or homework.

Researchers in Australia have inquired if international students in engineering may cheat more often compared to their domestic counterparts [25]. This study found that international engineering students are often initially unclear about what constitutes academic dishonesty. After instructing these students on what constituted academic dishonesty, they did not perform differently than domestic students [25]. Although international students may be initially unclear on what constitutes cheating, PACES-2 found no correlation between an engineering student's international status and their inclination to cheat [12]. It seems that initial instruction on what is expected of international students could eliminate any additional predilection toward academic dishonesty. Engineering is a popular choice for international students in Canada and any differences could be revealed with research focused on Canadian international students.

\section{OTHER FACTORS THAT INFLUENCE ACADEMIC DISHONESTY}

Beyond demographic factors, the researchers behind PACES-1 and PACES-2 explored the ethical decision making patterns of engineering students. Understanding what contextual and situational factors influence students' decisions to cheat can provide ethics policy makers with better tools to encourage academic integrity as well as material to help direct ethics instruction. The following are contextual and situational factors that influence students' decisions to be academically dishonest: moral obligation, type of assessment, and neutralizations.

\subsection{Moral Obligation}

One of the most important concepts in understanding what influences engineering students to be dishonest is moral obligation. Proposed by Harding et al. [13], moral obligation is a construct added to Ajzen's Theory of Planned Behavior [1]. In regards to cheating, moral obligation is a sense of responsibility that leads to a refusal to perform the cheating behaviour [12]. Moral obligation provides insight into how engineering students develop an intention to cheat. Harding et al. [12] proposed that there are four variables that influence a sense of moral obligation: fraternity/sorority participation, US citizenship, anti-social orientation, and past high school cheating behaviour. Our paper will review high school cheating and fraternity/sorority participation as they are the most strongly linked to moral obligation.

The results of the PACES-1 and PACES-2 surveys found that past cheating in high school strongly influenced engineering students' academic integrity [12] [22]. As engineering students begin their academic careers, their views on academic integrity will be influenced by their previous experiences in high school. Past cheating behaviour was significantly linked with reducing a sense of moral obligation and subsequently altering a student's intention to engage in academic dishonesty [12]. However, not all students who cheat in high school will continue this behaviour in college or university. Research suggests the number of engineering students who self-report cheating decreases between high school and postsecondary [12]. An explanation for this is that there is greater peer disapproval of cheating in postsecondary settings than in high school [21]. This contextual, peer-disapproval could be a powerful factor in influencing the sense of moral obligation among engineering students.

Association with fraternities and sororities has consistently been found to be associated with higher levels of academic dishonesty [12] [20] [22]. The PACES-2 survey revealed that involvement with these groups provided a social context which reduced an engineering student's sense of moral obligation towards academic integrity, increasing the likelihood of academic dishonesty 
[12]. Harding et al. [12] suggested that these groups create a social environment in which academic dishonesty is considered acceptable behaviour. Although not as common in Canada, there are sororities/fraternities or similar groups on campuses across the country. They may prove to be just as influential on a student's sense of moral obligation as those same societies in the United States.

\subsection{Type of Assessment}

All forms of cheating are often grouped into one category by researchers. Although an effort has been made by some researchers to categorize different forms of cheating, Passow et al. [22] reports that researchers often erroneously default to aggregating all types of academic cheating under a single variable for analysis such as "academic misconduct" or "academic dishonesty". This removes any ability to find unique predictors that may differ between behaviours. The results of the PACES-1 survey demonstrated that different types of assessment influenced the decisions of engineering students to engage in academic dishonesty [22]. They found that cheating behaviour varied between these forms of assessment and that predictors were often correlated with one assessment and not with another. For example, cheating on exams was more often reported by students attending college on scholarship than those who were paying their own way [22]. However, this trend was not observed in homework cheating. This is an example of how academic dishonesty rates can change based on the type of assessment and other student characteristics.

\subsection{Neutralizations}

Many students willingly engage in behaviours that they consider to be cheating [5]. Students are able to do this by neutralizing or rationalizing their unethical behaviour. There are many types of neutralizations, but most of these fall into the categories of societal blame or institutional blame. Societal blame consists of passing responsibility for dishonest behaviour onto peers and forces beyond the student's control. A study done by Bertram Gallant et al. [2] on a cheating incident within an undergraduate engineering course found that half of the implicated students blamed peer norms and family or personal issues as causes of their cheating.

Institutional blame consists of putting responsibility for academic dishonesty on the instructors. Often a disconnect exists between faculty and students on what constitutes academic dishonesty [5]. Students insist that faculty and administrators are responsible for preventing cheating. This held true in the cheating incident reported in Bertram Gallant et al. [2] where $16 \%$ of the involved students denied all responsibility for their academic dishonesty and neutralized their behaviour by blaming the professor and the institution. It seems that the apparent disconnect between students and their instructors may allow some students to deflect responsibility for their own unethical behaviour.

\section{POSSIBLE WAYS TO STOP CHEATING}

The main motivator of most academic dishonesty researchers in engineering is the reduction of the cheating behaviour, although most research in this area continues to focus on incidence. In the engineering education literature, two related prevention strategies are addressed: increasing student awareness and skills, and enhancing the ability to apply ethical principles.

\subsection{Increasing Student Awareness and Skills}

Researchers of ways to stop cheating often prescribe early training and regular practice in adhering to the rules and protocols of academic honesty [2]. Where assignments make use of proofs, algorithms, graphic designs, circuit diagrams, and programming languages, the notions of original work and referencing appearing in policies applicable to a general student body may not translate well to programs like engineering [24].

Two studies of note examined first-year engineering students in Australia. Focusing on matters of plagiarism, the first study found that while students could provide a solid definition of plagiarism, they could not always recognize plagiarism in practice [28]. Comparing students' self-reports, the second study found that international students were more likely than their domestic counterparts to report little to no prior instruction in avoiding plagiarism and were more likely to describe violators as lacking in knowledge rather than lacking in honesty [26].

Reporting on two cohorts of engineering students, surveyed 10 years apart (in 2002 and 2012), researchers observed some differences following a decade of awareness-building and other strategies [27]. In the decade between surveys, the institution:

- refined its academic integrity code,

- added content to orientation activities/handbooks,

- asked incoming students to sign an academic integrity pledge,

- suggested faculty include academic dishonesty rules in syllabi, and

- encouraged faculty to bring suspected violators forward to hearing processes.

The change in student self-reports was positive for the most part, with an increased awareness of academic integrity overall, an increased belief that faculty do follow up on violations, and a reduction in reports of exam cheating. Remaining unchanged were explanations given by students for academic dishonesty and the rates reported for cheating on homework assignments. 


\subsection{Improving Abilities to Apply Ethical Principles}

Ethics education is considered essential by many in the preparation of professional engineers [23]. Finelli et al. [9] found the overall quantity and quality of ethics related educational experiences to be high in their SEED study. Yet the measures of ethical reasoning ability of their sample, while falling in a normal range compared to other university students, placed engineering students generally at the lower end compared to those in other fields of study. This may reflect an associated finding highlighted earlier in this paper; engineering students have higher selfreported rates of academic dishonesty compared to most of their peers in university study.

In a recent publication, it was argued that ethics education has the potential to engender increased commitment to academic integrity [6]. Questions of academic integrity bring ethical sensitivity and reasoning to a more personal level. Using the lived experience of students when faced with academically dishonest choices ranging from questionable short-cuts to full-on cheating allows students to translate the theoretical perspective of ethics to their own lives. While case studies that feature high profile events are commonly used in engineering ethics education [8] [23], using cases that position students as agents, rather than observers, in more commonly-faced types of ethical dilemmas, is more likely to engage students in the relevance of ethical decision-making frameworks [23].

In apparent opposition to the above assertions, a study involving focus groups at 18 engineering programs, on the topic of goals and impacts of ethics education, found that the use of academic integrity cases was not helpful according to students [15]. Specifically, students regarded dilemmas of this kind to be "black-and-white" issues and did not translate them into engineering practice. Nonetheless, the researchers did not recommend abandoning academic integrity issues as teaching tools. They suggested that such tools can serve as effective starting points that require explicit translation to other kinds of ethical dilemmas.

Findings from PACES-1 have categorized students' viewpoints about various behaviours as i) cheating, ii) unethical but not cheating, or iii) neither [5]. Generally, there is agreement among students that during exams one should not copy from others or use concealed notes. There is less agreement about collaborating or consulting with fellow students on homework, knowing that individual work is expected to complete assignments [5]. It seems the more tightly controlled the assessment setting, the more likely any violations of the "rules" will be regarded as cheating.

\section{OUR SURVEY}

As previously noted, the authors of this paper have undertaken a pilot study on the perceptions and attitudes of cheating amongst engineering community members at the Universities of Saskatchewan and Regina. We were fortunate to have received permission from Dr. Trevor Harding and the $\mathrm{E}^{3}$ research group to base our survey on the PACES-1 survey tool [5]. The use of this survey tool will provide data that can be compared with existing American data sets to see if any expectations of differences can be validated. PACES-1 was reviewed and augmented with questions applicable to both the Saskatoon and Regina campuses.

The modified survey tool for the two Saskatchewan campuses was submitted for joint ethics approval in paper and electronic (FluidSurveys ${ }^{\mathrm{TM}}$ ) formats, and was targeted at three groups: undergraduates, graduate students, and instructors of the two engineering colleges/faculties.

The paper versions of the survey were distributed to two specific senior undergraduate classes; GE 449 Engineering in Society at the University of Saskatchewan, and ENGG 401 Engineering Law and Professionalism, at the University of Regina. The intent in using the paper surveys was to capture a specific, identifiable student sample from undergraduates currently studying issues of ethics in their coursework, as well as to capture respondents from all engineering disciplines.

As of the last week of April 2016, approximately 15\% of the total target population had responded from the University of Regina, and approximately $20 \%$ of the target population had responded from the University of Saskatchewan.

During the summer of 2016, the survey data will undergo validation and analysis with the results being available to interested parties by the Fall of 2016 .

\section{CONCLUSIONS/RECOMMENDATIONS}

In an American context, engineering students selfreport academic dishonesty at a higher rate than other disciplines. This pattern presents itself quite differently with various types of cheating. For example, reports of cheating on exams are much lower than cheating on homework assignments. There is some evidence to suggest that males cheat more often than females, but these results may be quite sensitive to demographic trends. Likewise, the significance of year of study (e.g. first-year versus senior years) is somewhat unclear. What is clear is that stress correlates well with cheating and this factor manifests itself in varied ways. High achieving students seem to cheat less, perhaps on this basis. Students heavily engaged in extracurricular activities are more likely to report cheating, again possibly due to their increased stress vis-à-vis workload. International engineering students have not been found to cheat more than domestic students, 
especially if trained to understand what constitutes cheating in a North American postsecondary setting. What has been found to influence cheating is the permissiveness of cheating in high school, and membership in fraternities or sororities. Peer pressure can help or hinder efforts to curb academic dishonesty. Nevertheless, many students will rationalize cheating behaviours by blaming instructors and/or administrators for stressors such as high workloads. Efforts to curb cheating in undergraduate engineering have consisted of increasing awareness and knowledge about cheating, developing theory and skills in applying ethical principles, and working through case studies of various sorts. The effectiveness of these techniques is still unclear.

We recommend conducting studies in Canada similar to PACES-1, PACES-2 and SEED, with the intent of assessing the scale and nature of the problem here, comparing and contrasting our findings with American data, and refining these tools based on what has been learned across the body of the cheating literature. We should look at the previously identified factors, and start to move towards assessing the effectiveness of specific interventions, where possible. Such applied research will add to the literature, and will help indicate precisely how cheating can be curbed by focusing the best messages on the students most in need of guidance. As well, any data that can be gathered that compares and contrasts the opinions of students and their instructors on these matters is expected to be valuable.

We do not expect many dramatic differences between Canadian and American schools. However, given the differences between how most postsecondary education is funded in the US and Canada, there may be residual effects highlighted by differences in stress levels and cheating behaviours associated with that factor.

\section{Acknowledgements}

The authors would like to thank Don Listwin, funder of the Huff Chair at the University of Saskatchewan, for his vital support. Huff Chair research funding made this work possible. We would also like to thank Dr. Trevor Harding of California Polytechnic and the $\mathrm{E}^{3}$ team for letting us use their Perceptions and Attitudes toward Cheating among Engineering Students (PACES-1) test battery, and for sharing sage advice. As well, we appreciate the support of the Engineering Student Centre (Saskatchewan), the Dean's Office (Regina), and the instructors of GE 449 and ENGG 401 for their help in distributing our survey. Finally, we want to thank Sarah Sangster for her help with FluidSurveys ${ }^{\mathrm{TM}}$, and the members of InTREEg (Innovative Teaching and Research in Engineering Education Group) this past year for their help and input during the development of this study.

\section{References}

[1] Icek Ajzen, "The theory of planned behavior," Organizational Behavior and Human Decision Processes, vol. 50, pp. 179-211, 1991.

[2] Tricia Bertram Gallant, Lelli Van Den Einde, Scott Ouellette, and Sam Lee, "A systemic analysis of cheating in an undergraduate engineering mechanics course," Science and Engineering Ethics, vol. 20, pp. 227-298, 2014.

[3] Angela Bielefeldt, "Perceptions of cheating behaviors by freshman engineering students," in Proc. ASEE 2009 Annual Conference \& Exposition, (Austin, TX; 14-17 June 2009), 11 pp., 2009.

[4] William Joseph Bowers, Student Dishonesty and its Control in College. New York, NY: Bureau of Applied Social Research, Columbia University, 1964, 399 pp.

[5] Donald D. Carpenter, Trevor S. Harding, Cynthia J. Finelli, Susan M. Montgomery, and Honor J. Passow, "Engineering students' perceptions of and attitudes towards cheating," Journal of Engineering Education, vol. 95, no. 3, pp. 181-194, July 2006.

[6] Julia M. Christensen-Hughes and Tricia Bertram Gallant, "Infusing ethics and ethical decision making into the curriculum," in Handbook of Academic Integrity. Singapore: Springer Singapore, Tracey Bretag (ed.), 2016, 1097 pp. \{ISBN: 978-981-287-097-1\}.

[7] Julia M. Christensen-Hughes and Donald L. McCabe, "Academic misconduct within higher education in Canada," Journal of Higher Education, vol. 36, no. 2, pp. 1-21, July 2006.

[8] Anne Colby and William M. Sullivan, "Ethics teaching in undergraduate engineering education," Journal of Engineering Education, vol. 97, no. 3, pp. 327-338, July 2008.

[9] Cynthia J. Finelli, Matthew A. Holsapple, Eunjong Ra, Rob M. Bielby, Brian A. Burt, Donald D. Carpenter, Trevor S. Harding, and Janel A. Sutkus, “An assessment of engineering students' curricular and co-curricular experiences and their ethical development," Journal of Engineering Education, vol. 101, no. 3, pp. 469-494, July 2012.

[10] Valerie J. Haines, George M. Diekhoff, Emily E. LaBeff, and Robert E. Clark, "College cheating: immaturity, lack of commitment, and the neutralizing attitude," Research in Higher Education, vol. 25, no. 4, pp. 342-354, December 1986. 
[11] Darcy Hango, Gender Differences in Science, Technology, Engineering, Mathematics and Computer Science (STEM) Programs at University. Ottawa, CA: Statistics Canada Catalogue Number 75-006-X - Minister of Industry, 2013, $13 \mathrm{pp}$.

[12] Trevor S. Harding, Donald D. Carpenter, and Cynthia J. Finelli, "An exploratory investigation of the ethical behavior of engineering undergraduates," Journal of Engineering Education, vol. 101, no. 2, pp. 346-374, April 2012.

[13] Trevor S. Harding, Matthew J. Mayhew, Cynthia J. Finelli, and Donald D. Carpenter, "The theory of planned behavior as a model of academic dishonesty in engineering and humanities undergraduates," Ethics and Behavior, vol. 17, no. 3, pp. 255-279, 2007.

[14] L.C. Hensley, K.M. Kirkpatrick, and J.M. Burgoon, "Relation of gender, course enrollment, and grades to distinct forms of academic dishonesty," Teaching in Higher Education, vol. 18, no. 8, pp. 895-907, 2013.

[15] Matthew A. Holsapple, Donald D. Carpenter, Janel A. Sutkus, Cynthia J. Finelli, and Trevor S. Harding, "Framing faculty and student discrepancies in engineering ethics education delivery," Journal of Engineering Education, vol. 101, no. 2, pp. 169-186, April 2012.

[16] Rozzet Jurdi, H. Same Hage, and Henry P. H. Chow, "Academic dishonesty in the Canadian classroom: behaviours of a sample of university students," Canadian Journal of Higher Education, vol. 41, no. 3, pp. 1-35, 2011.

[17] James S. Leming, "Cheating behavior, subject variables, and components of the internal-external scale under high and low risk conditions," Journal of Educational Research, vol. 74, no. 2, pp. 83-87, 1980.

[18] Norma Mattei, "Comparison of cheating behaviors in undergraduate engineering students and the general student population at the University of New Orleans," in Proc. ASEE 2008 Annual Conference \& Exposition, (Pittsburgh, PA; 22-25 June 2008), 13 pp., 2008.

[19] Donald L. McCabe, "Classroom cheating among natural science and engineering majors," Science and Engineering Ethics, vol. 3, no. 4, pp. 433-445, 1997.
[20] Donald L. McCabe, and Linka Klebe Trevino, "Individual and contextual influences on academic dishonesty: a multicampus investigation," Research in Higher Education, vol. 38, no. 3, pp. 379-396, June 1997.

[21] Donald L. McCabe, Linda Klebe Trevino, and Kenneth D. Butterfield, "Cheating in academic institutions: a decade of research," Ethics and Behavior, vol. 11, no. 3, pp. 219$232,2001$.

[22] Honor J. Passow, Matthew J. Mayhew, Cynthia J. Finelli, Trevor S. Harding, and Donald D. Carpenter, "Factors influencing engineering students' decisions to cheat by type of assessment," Research in Higher Education, vol. 47, no. 6, pp. 643-684, September 2006.

[23] Andrew Roncin, "Thoughts on engineering ethics education in Canada," in Proc. 2013 Canadian Engineering Education Association Conf., CEEA13, (Montreal, QC; 17-20 June 2013), 5 pp., 2013.

[24] Simon, "Academic integrity in non-text based disciplines," in Handbook of Academic Integrity. Singapore: Springer Singapore, Tracey Bretag (ed.), 2016, 1097 pp. \{ISBN: 978-981-287-097-1\}.

[25] Brad Stappenbelt, "Plagiarism in mechanical engineering education: a comparative study of international and domestic students," International Journal of Mechanical Engineering Education, vol. 40, no. 1, pp. 24-41, January 2012.

[26] Brad Stappenbelt and Chris Rowles, "Plagiarism in firstyear engineering education: a snapshot of student attitudes and abilities," in Proc. 2010 AAEE Conference, (Sydney, AUS; 5-8 December 2010), 8 pp., 2010.

[27] Sami W. Tabsh, Hany A. El-Kadi, and Akmal Abdelfatah, "Past and present engineering students' views on academic dishonesty at a middle-eastern university," International Journal of Engineering Education, vol. 31, no. 5, pp. 1334-1342, December 2014.

[28] Shelley Yeo, "First-year university science and engineering students' understanding of plagiarism," Higher Education Research \& Development, vol. 26, no. 2, pp. 199-216, June 2007. 